\title{
Is Epstein-Barr Virus a Risk Factor for Multiple Sclerosis?
}

\author{
Aktham Ismail Alemam ${ }^{\mathrm{a}, \mathrm{b}}$, Mostafa Saleh Maleek ${ }^{\mathrm{a}}$
}

\begin{abstract}
Background: The immune system is involved in the development of multiple sclerosis (MS) in genetically predisposed persons who are exposed to certain environmental stimuli that may include EpsteinBarr virus (EBV). The aim of the present study is to evaluate if EBV is an environmental risk factor in MS patients in Egyptian population.

Methods: This is a prospective comparative study of 41 patients (18 - 50 years) including 25 females and 16 males versus 41 age-gender matched healthy controls tested for different EBV antibodies through serological examination using ELISA test after taking their informed consent. The data analysis was performed using Graphpad Prism 6.0 software.
\end{abstract}

Results: Thirty-one patients were of relapsing-remitting MS (RRMS), eight cases were clinically isolated syndromes (CIS) and two cases were primary progressive MS (PPMS). Expanded disability status scale (EDSS) score of patients ranged from 0 to 8. Anti-EBV-viral capsid antigen (VCA)-IgG, anti-EBV-early antigen (EA)-IgG and anti-EBV-EBV nuclear antigen 1 (EBNA1)-IgG antibodies showed no statistically significant difference between MS and control groups with $P$ values of $0.083,0.517$ and 0.833 , respectively. No significant statistical correlation was found between level of EBV antibodies and MS clinical type, relapse or previous viral infection.

Conclusion: According to our study, EBV infection might not be an independent factor in the development of MS in Eyptian population.

Keywords: Epstein-Barr virus; Multiple sclerosis

\section{Introduction}

Multiple sclerosis (MS) is a complex heterogeneous, inflammatory disease characterized by loss of the myelin sheath that surronds the nerve axons in the brain, cerebellum and spinal

Manuscript submitted June 12, 2018, accepted August 6, 2018

${ }^{a}$ Neurology Department, Faculty of Medicine, Menoufia Univrsity, Al Minufya, Egypt

bCorresponding Author: Aktham Ismail Alemam, Neurology Department, Faculty of Medicine, Menoufia Univrsity, Al Minufya, Egypt.

Email: e_aktham@yahoo.com

doi: https://doi.org/10.14740/jnr490w cord [1]. Understanding the triggers and mechanisms behind the inflammatory process associated with MS is considered the largest obstacle in primary prevention and in developing effective treatment. It is thought that the immune system of the body is involved in the development of MS in the persons who are genetically predisposed and then exposed to certain environmental stimuli $[2,3]$. Some accumulating data point to Epstein-Barr Virus (EBV) to play a role in the pathogenesis of MS [4-7]. It is one of the members in the herpes family of viruses that are commonly present in humans. EBV primarily targets the memory B cells and remains latent in them. Depending on the type of latency, EBV gives different sets of latent products $[8,9]$. EBV is well known for its close relationship with the immune system [10]. It is generally believed that some EBV-associated pathologies come as a result of the disruption of the virus-host immune system balance, and clinical symptoms and signs of EBV infection emerge as a result of induced immune response rather than of EBV itself [11]. In this context, several groups have shown that in MS, the immune response directed towards EBV is disrupted [12].

There are three hypothetical mechanisms that are supposed to link EBV and MS through B cells. These include either the reactivation of EBV in the memory B cells in the central nervous system (CNS) [13], presence of cross-reactivity of anti-EBV antibodies to human proteins in the CNS (molecular mimicry) [14], or helping in the facilitation of "forbidden" memory B cells to recognize an antigen in the CNS [15]. Seroepidimiological studies have reported that 100\% of MS patients are infected with EBV in contrast to $95.8 \%$ of healthy age-matched controls [16]. It is postulated that elevated titers of anti-EBV nuclear antigen 1 (EBNA1)-specific IgG have been associated with an increased risk of subsequent development of MS [17]. There are three recent meta-analyses showing that EBV seropositivity substantially increases the risk of MS (4.5-fold, 5.5-fold or 16-fold, respectively, depending on the study) [18-20]. Also, others have found a relation between EBV reactivation as studied by early antigen (EA) and disease activity in MS patients [21].

However, the relation between EBV and MS is not universally accepted as some studies have failed to consistently prove the presence of the virus in MS brains [22, 23]. Also, the very low levels of EBV in the body suggest that a direct immune response against EBV appears to be an unlikely cause of MS [24]. Additionally, MS is rare in children, meaning that EBV infections are insufficient to cause MS on their own [25].

In this study, we tried to evaluate the role of EBV as a risk factor in MS patients in our community sample in Egypt through serological examination. 


\section{Patients and Methods}

\section{Patients}

Blood samples were collected from 41 untreated cases of MS during their diagnosis and before initiating any medical treatment at Neurology Department, Minoufia University Hospitals, Egypt, from November 2015 till December 2017 after taking their consent to participate this research. The diagnosis of MS was established based on clinical, laboratory and MRI findings, according to modified McDonald's criteria (2010) [26]. There were no selection bias in this study. The duration of follow-up to detect relapses was for 6 months.

\section{Controls}

Gender- and age-matched control serum samples were obtained from 41 healthy controls.

Twenty-two patients $(53.7 \%)$ showed a positive history of previous viral infection (upper respiratory tract infection), while 19 patients $(46.3 \%)$ had no history of previous viral infectin.

\section{Antibody detection and quantification}

Serum samples of patients with MS and controls were stored frozen below $20^{\circ} \mathrm{C}$. Patient and matched control samples were analyzed in parallel, blinded to case status, to obtain optimal comparability. Antibody levels were measured by standardized and European Community certified tests. ELISA classic (Virion Serion, Wuerzburg, Germany) was used to test for EBV-viral capsid antigen (VCA)-IgG, EBV-EBNA1-IgG and EBV-EA-IgG $\mu$. Amounts of $100 \mu \mathrm{L}$ of 1:100 diluted sera were analyzed in antigen-coated microwells. Alkaline phosphataseconjugated anti-human IgG from goat (polyclonal) and paranitrophenylphosphate substrate were used, followed by incubation for $30 \mathrm{~min}$ and then adding $100 \mu \mathrm{L}$ stopping solution to each well and shaking the micro test plate gently to mix. Optical density values were measured within 60 min at $405 \mathrm{~nm}$ against blank substrate; reference wave length was between 620 and $690 \mathrm{~nm}($ e.g. $650 \mathrm{~nm})$.

\section{Statistical analysis}

The analysis was performed using Graphpad Prism 6.0 software. Fisher exact test with Yate's corrections was used to compare VCA, EA and EBNA1 antibody titers between MS patients and controls.

\section{Results}

Patients age was ranging from 18 - 50 years with mean \pm SD of $31.66 \pm 7.95$, including 25 females $(61 \%)$ and 16 males $(39 \%)$, in addition to 41 age- and gender-matched healthy control subjects after taking their consent.

\section{Clinical characteristics of MS patients}

Type of $M S$

Thirty-one cases $((75.6 \%)$ with RRMS (relapsing-remitting MS); 8 cases $(19.5 \%$ ) with clinically isolated syndromes (CIS) and 2 cases $(4.9 \%)$ presented with PPMS (primary progressive MS).

\section{Initial clinical presentation}

Nineteen cases with optic neuritis, 14 cases presented with sensory symptoms like hemi- paresthesias, Lhermitte's sign, tingling and/or numbness, 12 cases with hemiparesis; 8 cases with cerebellar manifestations; 1 case with dysarthria; 5 cases with paraparesis, 4 cases with generalized tonic colonic seizure; 2 cases with manifestations of increased intracranial pressure (ICP).

\section{Number of relapses}

In our study, 11 patients $(26.8 \%)$ showed no relapses, 12 patients $(29.3 \%)$ showed one relapse, 11 patients $(26.8 \%)$ showed two relapses, 6 patients $(14.6 \%)$ showed three relapses and only one patient $(2.4 \%)$ showed four relapses.

\section{Expanded disability status scale (EDSS) of the patients}

It ranged between 0 and 8 with a mean (2.8) and SD (1.564): one patient was scaled as 0 which means no disability, two patients had 1 on scale, two patients had a 1.5 on scale, seven patients had 2 on scale, six patients had 2.5 , twelve patients had 3 , five patients had 3.5, one patient had 6.5 and two patients had 8 on scale.

\section{EBV antibodies}

Regarding antibodies against EBV, we found that anti-EBVVCA-IgG was positive in all patients and the control group; in the patients' group, the titers ranged from 30 to 200 with a mean $\pm \mathrm{SD}$ of $135.73 \pm 58.54$, while in the control group, it ranged from 35 to 200 with a mean $\pm \mathrm{SD}$ of $114.22 \pm 52.09$, which showed no significant difference $(P=0.083)$. Also, anti EBV-EA-IgG was positive in all patients and control group; in the patients' group, the titers ranged from 10 to 180 with a mean $\pm \mathrm{SD}$ of $54.56 \pm 36.22$, while in the control group, it ranged from 13 to 170 with a mean $\pm \mathrm{SD}$ of $49.78 \pm 30.0$, which was statistically non-significant $(\mathrm{P}=0.517)$. In addition, anti-EBV-EBNA1-IgG was positive in all patients and the control group; in patients' group, the titers range from 1.7 to 150 
Table 1. The Relations Between EBV Titers in MS Patients and History of Previous Viral Infection

\begin{tabular}{lllll} 
& & Viral infection & T value & P value \\
\cline { 2 - 4 } & Negative $(\mathbf{n}=\mathbf{1 9})$ & Positive $(\mathbf{n}=\mathbf{2 2})$ & -0.498 & 0.622 \\
\hline Anti-EBV-VCA-IgG & $30.79 \pm 63.77$ & $140.00 \pm 54.77$ & -0.313 & 0.756 \\
Anti-EBV-EA-IgG & $52.63 \pm 38.17$ & $56.23 \pm 35.26$ & 1.514 & 0.145 \\
Anti-EBV-EBNA1-IgG & $27.04 \pm 32.92$ & $15.12 \pm 10.43$ & & \\
\hline
\end{tabular}

Table 2. The Relation Between EBV Levels and Different Types of MS

\begin{tabular}{lllll} 
& CIS $(\mathbf{n}=\mathbf{8})$ & RRMS (n=31) & PPMS (n= 2) & P value \\
\hline Anti-EBV-VCA-IgG & $137.38 \pm 56.70$ & $135.68 \pm 61.77$ & $130.00 \pm 0.0$ & 0.988 \\
Anti-EBV-EA-IgG & $47.00 \pm 16.04$ & $57.90 \pm 40.34$ & $33.00 \pm 9.90$ & 0.528 \\
Anti-EBV-EBNA1-IgG & $32.75 \pm 48.52$ & $18.04 \pm 13.22$ & $12.50 \pm 2.12$ & 0.278 \\
\hline
\end{tabular}

with a mean (20.64) and SD (24.1), while in the control group, it ranged from 10 to 80 with a mean (19.71) and SD (14.94), which also was statistically non-significant $(\mathrm{P}=0.833)$.

There was no significant difference between EBV titers in MS patients and history of previous viral infection (Table 1).

Also, there was no significant difference in EBV levels in relation to different types of presentation, but the levels seemed to be lower in patients with primary progressive MS (Table 2 and Fig. 1).

Regarding EBV profile in relation to occurrence of relapses, there was no significant difference (Table 3). In addition, there was no significant relation between the age in patients' group and EBV levels.

\section{Discussion}

There is still a great debate over whether the association between EBV infection and MS is a chance or if, on the oppo-

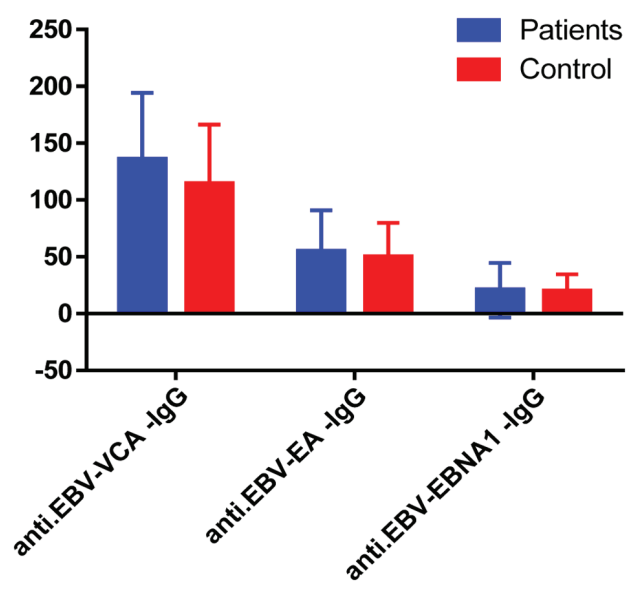

Figure 1. Comparison between the serum levels of EBV biomarkers: anti-EBV-viral capsid antigen (VCA)-IgG, anti-EBV-early antigen (EA)$\lg$ and anti-EBV- EBV nuclear antigen 1 antibody (EBNA1)-IgG of both patients and controls with no significant difference between both groups. site side, there is a pivotal relationship, single or multiple [27]. Although some studies support a role for EBV in MS [28], no proposed mechanism has been able to convincingly explain this link so far [29, 30].

In this study, we evaluated the role of EBV as a risk factor in MS patients. The most apparent results of our study were the presence of anti-EBV antibodies in all patients and controls which might indicate the high prevalence of EBV infection in our community in Egypt. These results coincide with published data about the high seroprevalence of EBV in Egypt with a rate between $60 \%$ and $86 \%$ [31].

\section{Anti-EBV-VCA-IgG titers}

In our series, anti EBV-VCA-IgG titers were positive in all patients and the control group, which coincides with some published reports [32]. Sundstrom and colleagues reported on a large series involving 234 patients versus 693 controls that anti-EBV-VCA-IgG was positive in both patients with MS and controls in a percentage of $100 \%$ and $98.7 \%$ respectively; they also reported that the titers were higher in the patient group, but did not reach a statistical significant value [33]. Also, Ascherio and colleagues concluded that EBV-VCA-IgG was present in both MS patients and controls in a percentage of $99.3 \%$ and $93.4 \%$ respectively in their study [29].

Zivadinov and colleagues found in their study upon 133 patients versus 131 healthy controls that the prevalence of VCA was $95 \%$ and $100 \%$ of patients and controls, respectively [34]. Castellazzi and colleagues reported that VCA antibodies were lower in MS patients; however, the authors used controls with neurological disorders who are not healthy controls as in our and other reports [35]. Conversly, Mouhieddine et al reported that the titers of EBV-VCA were significantly higher in patients than those in control group [36].

\section{Anti-EBV-EA-IgG}

In our study, the titers of anti EBV-EA-IgG were positive in all 
Table 3. The Relation Between EBV Titers and MS Relapses

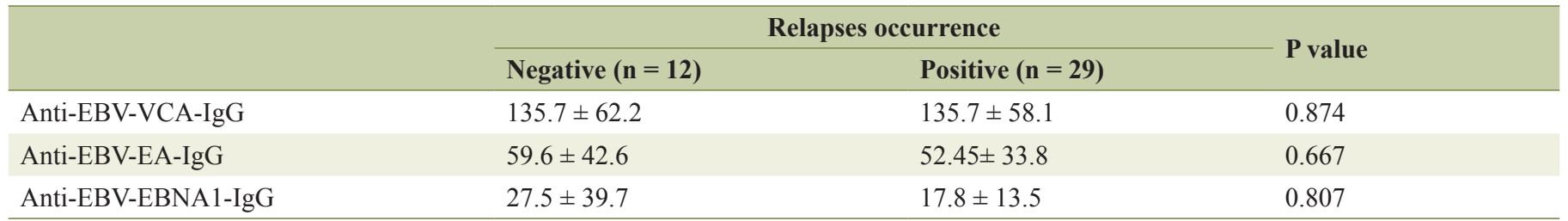

patients and control group. Antibodies against EA are of interest as they may indicate active EBV replication as if EBV infection is driving the immune response in MS, then we would expect increased anti-EA in relapse compared to stable disease and with MS compared to controls. There is suggestive experimental evidence that this may be the case [37].

There was a great controversy in published series: some series showed high prevalence and significance of EA in the patient group, other series showed lower seropositivity in both groups, while others showed high prevalence in controls than in patients.

Contrary to our findings, Buljevac and colleagued reported the presence of anti-EBV-EA in $41.9 \%$ and $23.3 \%$ of patients and controls, respectively [38].

Also Kjell-Morten and coleagues reported much higher prevalence rates for anti-EBV-EA-IgG, 68.8\% in patients and $46.5 \%$ in control subjects, with highly significant values in the patient group [39].

Lindsey et al. found that EBVNA1-IgG and EA-IgA were increased in MS compared to controls. EA-IgA had a median value of 1.964 in the patients with MS and 1.248 in the controls $(\mathrm{P}=0.029$, Wilcoxon signed-rank test) [40].

On the other hand, Wandinger and his colleagues reported that EA was of no significance as it was positive in $13.8 \%$ and $17.1 \%$ in patients and controls, respectively [41].

Also, Pohl included 147 patients versus 147 controls, and reported that EA was positive $6.1 \%$ versus $4.7 \%$, respectively [42].

Munch and his colleagues reported in their series that the prevalence of EA was higher in controls $(41.3 \%)$ than in patients $(36.2 \%)$ [43].

\section{Anti-EBV-EBNA1-IgG titers}

Our results of anti-EBV-EBNA1-IgG titers were in agreement with Honarmand et al, who found that seropositivity to antiEBNA1-IgG did not show a significant difference between the MS patients and control group $(92.9 \%$ and $88.4 \%$, respectively), and nor was seropositivity to anti-EBV-CA IgG different between the two groups (95.2\% and 95.3\%, consequently). Seropositivity to both anti-EBNA1 and anti-EBV-CA showed that past infection did not show significant associations with the later development of MS [44]. Banwell and his colleagues found a high prevalence of EBNA1 in both patients and control group, but this study was restricted to pediatric age group only [45]. Conversly, other investigators reported an increase in the prevalence or concentration of antibodies to EBNA1 in MS patients [46]. This might be because those studies worked upon EBNA1 titers in serum except some who worked upon CSF, reporting a highly significant difference in prevalence in patients $(79.7 \%)$ than controls $(14.5 \%)$ with a highly significant difference in titers between both of them [21]. Also, Lunemann reported that the persons who have increased antibody response to EBNA1 have higher odds ratio of developing MS when compared to those with baseline IgG titers to EBNA1 [21].

\section{EBV titers and MS relapse}

According to the correlation between EBV titers and relapse occurrence, we found it non-significant, which agrees with published series by Buljevac and colleagues who reported that there was no relationship between increased EA titers and exacerbations or clinical phenotype [38]. Also, Lindsey found that none of the antibody levels were altered in relapse [40]. Meanwhile, Wandinger and colleagues reported some indications for relatively more active EBV replication in a subgroup of $11 \mathrm{MS}$ patients with clinical exacerbations than in eight clinically stable patients [41]. The discrepancy between these two studies might be due to technical differences, such as the use of a different polymerase chain reaction (PCR) and the lack of cerebrospinal fluid (CSF) samples in our study. In their study, the significance was only reached after making a composite score of several serological tests together with PCR.

Generally, in the same direction of our results, Willis proved that EBV could not be detected in any of the MS specimens containing white matter lesions, yet EBV was readily detectable in multiple EBV control tissues including several CNS lymphomas. The CNS EBV infection was rare in MS brain and this may indicate that EBV infection is unlikely to contribute directly to MS brain pathology [23].

Sargsyan et al proved that no EBV RNA was found in MS CSF B-lymphocytes or plasma cells. The EBV-encoded RNA (EBER)-1 was the only and rarely detected transcript in active MS plaques. The frequency of detected intrathecal anti-EBV antibody synthesis in the patients with MS did not differ from that in non-MS inflammatory CNS disease control patients. They concluded that application of real-time PCR to MS brain and single B-lymphocytes in CSF did not reveal any evidence of active EBV infection [47].

Farrell et al proved that the correlation between elevated EBNA1-IgG and gadolinium-enhancing lesions may indicate the presence of association between EBV infection and the activity of MS disease. The heightened immune response to EBV in MS was specifically related to EBNA1-IgG, a marker 
of the latent phase of the virus. The deficiency of association between acute viral reactivation in the peripheral blood and gadolinium-positive lesions suggests a limited role of the former in driving MS activity [48].

The unreliable transmission of EBV during memory B-cell division may solve the absence of EBV in the CNS, while still allowing "forbidden" memory B cells to reach this site. However, no mechanism can explain the multi-decade delay between EBV infections in early childhood and MS in early adulthood [49]. The relative risk of MS in EBV carriers ( $>4.5$-fold) is difficult to be explained by EBV acting as a surrogate for other factors, as these factors would have be to extremely correlated with EBV exposure [29]. The anti-EBV antibodies that are present in the CNS [50] could unintentionally have a high attraction to human proteins through molecular mimicry, activating MS-causing inflammation in this site [51]. However, this simple mechanism fails to explain the multi-year delay between EBV seroconversion and MS onset in young adults, as anti-EBV antibodies precede MS onset by many years [52].

There were some limitations in this study. The numbers of the patients with clinically isolated syndromes (only eight patients) and cases with primary progressive MS (only two cases) were low and consequently, the relevance of a related statistical analysis of the results may be weak. Also, the duration of follow-up for relapses may be needed to be longer than 6 months for observation of more reapses.

\section{Conclusions}

EBV infection might not be an independent factor in the development of MS in our Egyptian population. Further studies are needed to prove or exclude the role of EBV in MS in other different regions.

\section{References}

1. Stadelmann $\mathrm{C}$, Wegner $\mathrm{C}$, Bruck W. Inflammation, demyelination, and degeneration - recent insights from MS pathology. Biochim. Et. Biophys. Acta (BBA)-Mol. Basis Dis. 2011;1812:275-282.

2. Belbasis L, Bellou V, Evangelou E, Ioannidis JP, Tzoulaki I. Environmental risk factors and multiple sclerosis: an umbrella review of systematic reviews and meta-analyses. Lancet Neurol. 2015;14(3):263-273.

3. Hemmer B, Kerschensteiner M, Korn T. Role of the innate and adaptive immune responses in the course of multiple sclerosis. Lancet Neurol. 2015;14(4):406-419.

4. Lassmann H, Niedobitek G, Aloisi F, Middeldorp JM, NeuroproMiSe EBVWG. Epstein-Barr virus in the multiple sclerosis brain: a controversial issue - report on a focused workshop held in the Centre for Brain Research of the Medical University of Vienna, Austria. Brain. 2011;134(Pt 9):2772-2786.

5. Dooley MM, de Gannes SL, Fu KA, Lindsey JW. The increased antibody response to Epstein-Barr virus in multiple sclerosis is restricted to selected virus proteins.
J Neuroimmunol. 2016;299:147-151.

6. Dunham J, van Driel N, Eggen BJ, Paul C, t Hart BA, Laman JD, Kap YS. Analysis of the cross-talk of EpsteinBarr virus-infected B cells with T cells in the marmoset. Clin Transl Immunology. 2017;6(2):e127.

7. Mostafa A, Jalilvand S, Shoja Z, Nejati A, Shahmahmoodi S, Sahraian MA, Marashi SM. Multiple sclerosis-associated retrovirus, Epstein-Barr virus, and vitamin D status in patients with relapsing remitting multiple sclerosis. J Med Virol. 2017;89(7):1309-1313.

8. Khan G, Miyashita EM, Yang B, Babcock GJ, ThorleyLawson DA. Is EBV persistence in vivo a model for B cell homeostasis? Immunity. 1996;5(2):173-179.

9. Babcock GJ, Decker LL, Volk M, Thorley-Lawson DA. EBV persistence in memory B cells in vivo. Immunity. 1998;9(3):395-404.

10. Brooks JM, Long HM, Tierney RJ, Shannon-Lowe C, Leese AM, Fitzpatrick M, Taylor GS, et al. Early T cell recognition of $\mathrm{B}$ cells following Epstein-barr virus infection: identifying potential targets for prophylactic vaccination. PLoS Pathog. 2016;12(4):e1005549.

11. Izawa K, Martin E, Soudais C, Bruneau J, Boutboul D, Rodriguez R, Lenoir C, et al. Inherited CD70 deficiency in humans reveals a critical role for the CD70-CD27 pathway in immunity to Epstein-Barr virus infection. J Exp Med. 2017;214(1):73-89.

12. de Paula Alves Sousa A, Johnson KR, Nicholas R, Darko $\mathrm{S}$, Price DA, Douek DC, Jacobson S, et al. Intrathecal Tcell clonal expansions in patients with multiple sclerosis. Ann Clin Transl Neurol. 2016;3(6):422-433.

13. Serafini B, Muzio L, Rosicarelli B, Aloisi F. Radioactive in situ hybridization for Epstein - Barr virus-encoded small RNA supports presence of Epstein-Barr virus in the multiple sclerosis brain. Brain J Neurol. 2013;136:e233e233.

14. Vaughan JH, Riise T, Rhodes GH, Nguyen MD, BarrettConnor E, Nyland H. An Epstein Barr virus-related cross reactive autoimmune response in multiple sclerosis in Norway. J Neuroimmunol. 1996;69(1-2):95-102.

15. Lunemann JD, Munz C. EBV in MS: guilty by association? Trends Immunol. 2009;30(6):243-248.

16. Giuseppe M, Davide C, Eleonora C, Speranza M, Jessica F, Maria G, et al. EBNA-1 IgG titres in Sardinian multiple sclerosis patients and controls. J Neuroimmunology. 2013;20:163-168.

17. Ingram G, Bugert JJ, Loveless S, Robertson NP. AntiEBNA-1 IgG is not a reliable marker of multiple sclerosis clinical disease activity. Eur J Neurol. 2010;17(11):13861389.

18. Almohmeed YH, Avenell A, Aucott L, Vickers MA. Systematic review and meta-analysis of the sero-epidemiological association between Epstein Barr virus and multiple sclerosis. PLoS One. 2013;8(4):e61110.

19. Ascherio A, Munger KL. Environmental risk factors for multiple sclerosis. Part I: the role of infection. Ann Neurol. 2007;61(4):288-299.

20. Pakpoor J, Disanto G, Gerber JE, Dobson R, Meier UC, Giovannoni G, Ramagopalan SV. The risk of developing multiple sclerosis in individuals seronegative for Epstein- 
Barr virus: a meta-analysis. Mult Scler. 2013;19(2):162166.

21. Lunemann JD, Tintore M, Messmer B, Strowig T, Rovira A, Perkal H, Caballero E, et al. Elevated EpsteinBarr virus-encoded nuclear antigen-1 immune responses predict conversion to multiple sclerosis. Ann Neurol. 2010;67(2):159-169.

22. Peferoen LA, Lamers F, Lodder LN, Gerritsen WH, Huitinga I, Melief J, Giovannoni G, et al. Epstein Barr virus is not a characteristic feature in the central nervous system in established multiple sclerosis. Brain. 2010;133(Pt 5):e137.

23. Willis SN, Stadelmann C, Rodig SJ, Caron T, Gattenloehner S, Mallozzi SS, Roughan JE, et al. Epstein-Barr virus infection is not a characteristic feature of multiple sclerosis brain. Brain. 2009;132(Pt 12):3318-3328.

24. Thorley-Lawson DA. EBV persistence - introducing the virus. Curr Top Microbiol Immunol. 2015;390(Pt 1):151209.

25. Confavreux C, Vukusic S. Natural history of multiple sclerosis: a unifying concept. Brain. 2006;129(Pt 3):606616.

26. Polman $\mathrm{CH}$, Reingold SC, Banwell B, Clanet M, Cohen JA, Filippi M, Fujihara K, et al. Diagnostic criteria for multiple sclerosis: 2010 revisions to the McDonald criteria. Ann Neurol. 2011;69(2):292-302.

27. Olsson T, Barcellos LF, Alfredsson L. Interactions between genetic, lifestyle and environmental risk factors for multiple sclerosis. Nat Rev Neurol. 2017;13(1):25-36.

28. Haahr S, Plesner AM, Vestergaard BF, Hollsberg P. A role of late Epstein-Barr virus infection in multiple sclerosis. Acta Neurol Scand. 2004;109(4):270-275.

29. Ascherio A, Munger KL. Epstein-barr virus infection and multiple sclerosis: a review. J Neuroimmune Pharmacol. 2010;5(3):271-277.

30. Tselis A. Epstein-Barr virus cause of multiple sclerosis. Curr Opin Rheumatol. 2012;24(4):424-428.

31. Biggar RJ, Henle W, Fleisher G, Bocker J, Lennette ET, Henle G. Primary Epstein-Barr virus infections in African infants. I. Decline of maternal antibodies and time of infection. Int J Cancer. 1978;22(3):239-243.

32. Pender MP. The essential role of Epstein-Barr virus in the pathogenesis of multiple sclerosis. Neuroscientist. 2011;17(4):351-367.

33. Sundstrom P, Juto P, Wadell G, Hallmans G, Svenningsson A, Nystrom L, Dillner J, et al. An altered immune response to Epstein-Barr virus in multiple sclerosis: a prospective study. Neurology. 2004;62(12):2277-2282.

34. Zivadinov R, Zorzon M, Weinstock-Guttman B, Serafin M, Bosco A, Bratina A, Maggiore C, et al. Epstein-Barr virus is associated with grey matter atrophy in multiple sclerosis. J Neurol Neurosurg Psychiatry. 2009;80(6):620625.

35. Castellazzi M, Contini C, Tamborino C, Fasolo F, Roversi G, Seraceni S, Rizzo R, et al. Epstein-Barr virus-specific intrathecal oligoclonal IgG production in relapsing-remitting multiple sclerosis is limited to a subset of patients and is composed of low-affinity antibodies. J Neuroinflammation. 2014;11:188.
36. Mouhieddine TH, Darwish H, Fawaz L, Yamout B, Tamim H, Khoury SJ. Risk factors for multiple sclerosis and associations with anti-EBV antibody titers. Clin Immunol. 2015;158(1):59-66.

37. DeLorenze GN, Munger KL, Lennette ET, Orentreich $\mathrm{N}$, Vogelman JH, Ascherio A. Epstein-Barr virus and multiple sclerosis: evidence of association from a prospective study with long-term follow-up. Arch Neurol. 2006;63(6):839-844.

38. Buljevac D, van Doornum GJ, Flach HZ, Groen J, Osterhaus AD, Hop W, van Doorn PA, et al. Epstein-Barr virus and disease activity in multiple sclerosis. J Neurol Neurosurg Psychiatry. 2005;76(10):1377-1381.

39. Myhr KM, Riise T, Barrett-Connor E, Myrmel H, Vedeler C, Gronning M, Kalvenes MB, et al. Altered antibody pattern to Epstein-Barr virus but not to other herpesviruses in multiple sclerosis: a population based case-control study from western Norway. J Neurol Neurosurg Psychiatry. 1998;64(4):539-542.

40. Lindsey JW, Hatfield LM, Vu T. Epstein-Barr virus neutralizing and early antigen antibodies in multiple sclerosis. Eur J Neurol. 2010;17(10):1263-1269.

41. Wandinger K, Jabs W, Siekhaus A, Bubel S, Trillenberg P, Wagner H, Wessel K, et al. Association between clinical disease activity and Epstein-Barr virus reactivation in MS. Neurology. 2000;55(2):178-184.

42. Pohl D. Epstein-Barr virus and multiple sclerosis. J Neurol Sci. 2009;286(1-2):62-64.

43. Munch M, Riisom K, Christensen T, Moller-Larsen A, Haahr S. The significance of Epstein-Barr virus seropositivity in multiple sclerosis patients? Acta Neurol Scand. 1998;97(3):171-174.

44. Honarmand H, Ahmadi Jalali Moghadam M, Hatamian H, Roudbary A. Possible relations between Epstein-Barr virus past infection and classic multiple sclerosis in Guilan, Iran. Jundishapur J Microbiol. 2015;8(6):e15985.

45. Banwell B, Krupp L, Kennedy J, Tellier R, Tenembaum S, Ness J, Belman A, et al. Clinical features and viral serologies in children with multiple sclerosis: a multinational observational study. Lancet Neurol. 2007;6(9):773-781.

46. Thacker EL, Mirzaei F, Ascherio A. Infectious mononucleosis and risk for multiple sclerosis: a meta-analysis. Ann Neurol. 2006;59(3):499-503.

47. Sargsyan SA, Shearer AJ, Ritchie AM, Burgoon MP, Anderson S, Hemmer B, Stadelmann C, et al. Absence of Epstein-Barr virus in the brain and CSF of patients with multiple sclerosis. Neurology. 2010;74(14):1127-1135.

48. Farrell RA, Antony D, Wall GR, Clark DA, Fisniku L, Swanton J, Khaleeli Z, et al. Humoral immune response to EBV in multiple sclerosis is associated with disease activity on MRI. Neurology. 2009;73(1):32-38.

49. Nanbo A, Sugden A, Sugden B. The coupling of synthesis and partitioning of EBV's plasmid replicon is revealed in live cells. EMBO J. 2007;26(19):4252-4262.

50. Cepok S, Zhou D, Srivastava R, Nessler S, Stei S, Bussow K, Sommer N, et al. Identification of Epstein-barr virus proteins as putative targets of the immune response in multiple sclerosis. J Clin Invest. 2005;115(5):1352-1360.

51. Lindsey JW, deGannes SL, Pate KA, Zhao X. Antibodies 
specific for Epstein-Barr virus nuclear antigen- 1 cross-react with human heterogeneous nuclear ribonucleoprotein L. Mol Immunol. 2016;69:7-12.
52. Levin LI, Munger KL, O'Reilly EJ, Falk KI, Ascherio A. Primary infection with the Epstein-Barr virus and risk of multiple sclerosis. Ann Neurol. 2010;67(6):824-830. 